\title{
Notas para a discussão do tempo na economia: uma modelagem heterodoxa
}

\author{
Notes for the discussion of time in economics: \\ a heterodox approach
}

ENÉAS G. DE CARVALHO*-

\begin{abstract}
RESUMO: O objetivo deste artigo é apresentar as principais contribuições heterodoxas (não deterministas) para a abordagem do tempo, em economia, e contrapô-las ao enfoque dominante. Adicionalmente, busca-se contribuir para o entendimento das razões pelas quais a concepção determinista do tempo ainda é dominante - e talvez hegemônica - entre os economistas. Esta situação tem permanecido assim apesar do fato de que a abordagem alternativa (não determinista) tenha se revelado mais adequada ao seu objeto e venha ganhando importância e atenção significativa em uma ampla gama de disciplinas científicas. Este artigo procura avançar uma hipótese explicativa para esta situação paradoxal e intrigante, sem ter, entretanto, a pretensão de dar uma resposta completa ou definitiva para esta importante e intrincada questão.
\end{abstract}

PALAVRAS-CHAVE: Tempo; Incerteza; Irreversibilidade; Diacronismo; Ex ante e Ex post.

ABSTRACT: The purpose of this paper is to present the main heterodox (not determinist) contributions to the time approach in economics. Also it is looking for to compare the dominant (determinist) view with the not determinist one. In addition, it seeks to contribute to the understanding of the reasons why the deterministic approach of time is still dominant - and perhaps hegemonic - among the economists. This circumstance has remained so despite the fact that the alternative view (not deterministic) has proved to be most appropriate to its object and it has been gaining importance and significant attention in a wide range of scientific disciplines. This article seeks to advance an explanatory hypothesis for this paradoxical and intriguing situation, without claim to offer, however, a complete or definitive answer to this important and intricate issue.

KEYWORDS: Time; Uncertainty; Irreversibility; Diachronism; Ex ante and Ex post. JEL Classification: B2; B5; B4; B1.

\footnotetext{
* Professor assistente do Departamento de Economia da Universidade Estadual Paulista (Unesp). E-mail: egcarvalho58@gmail.com. Submetido: 5/Fevereiro/2016; Aprovado: 23/Janeiro/2017.

- O autor deseja agradecer aos dois pareceristas anônimos cujos comentários e sugestões contribuíram, apreciavelmente, para a versão final deste artigo. Aplicam-se, entretanto, as ressalvas de praxe.
} 
“Mas não podemos prever o futuro com exatidão. $\mathrm{O}$ inesperado pode acontecer. $\mathrm{E}$ as tendências podem ser modificadas antes que tenham tido tempo de desempenhar o que agora parece ser o seu inteiro papel. O fato de não serem estacionárias as condições gerais da vida [...][O] elemento tempo é uma das principais causas daquelas dificuldades nas investigações econômicas que tornam necessário que o homem, com limitadas faculdades, não avance senão passo a passo, decompondo uma questão complexa, estudando um aspecto de cada vez, para, afinal, combinar as soluções parciais numa solução mais ou menos completa do problema total"

Marshall, 1985, V. II: 34 e 47; itálico acrescentado ${ }^{1}$

\section{INTRODUÇÃO}

Como várias outras ciências e disciplinas científicas, a economia adotou no século XIX o paradigma determinista da dinâmica newtoniana (Klein, 1997; Chick, 2010). Dentre os muitos economistas que reconheciam e/ou defendiam a inspiração na física por parte da economia (Mirowski, 1989)2, merecem ser destacados Marshall (V. I, 1982) ${ }^{3}$; Knight; Fisher e Samuelson (Mirowski, 1989) por terem se tornado economistas de grande prestígio e influência - status obtido não apenas pela circunstância de serem frequentemente considerados os maiores expoentes das suas respectivas gerações.

Com base em um extenso trabalho sobre o impacto da física sobre a economia e, portanto, de uma perspectiva mais abrangente, Mirowski (1989) mostrou que as influências da primeira sobre a segunda foram variadas e significativas, até $o$ início do século XX. "Embora ela era finalmente chamada 'energia' na física e 'utilidade' na economia, era a mesma metáfora fundamentalmente, desempenhando muitas das mesmas funções explicativas nos respectivos contextos, [...] sem men-

\footnotetext{
${ }^{1}$ A frase da epígrafe e, especialmente a parte em itálico, parece indicar um Marshall muito preocupado com a questão do tempo e com uma visão da mesma muito diferente dos seus contemporâneos. Como se verá mais adiante, trata-se apenas de uma meia verdade.

${ }^{2}$ Entre eles, deve-se mencionar, também, os economistas de inclinação matemática: Cournot, Walras, Jevons, Edgeworth e Pareto. Embora não fossem economistas com tendência matemática, Menger e J. S. Mill também devem figurar entre aqueles que defendiam a inspiração na física por parte da economia. Em relação às posições de J. B. Clark, Böhm-Bawerk, Cassel e Wicksel, não foi possível fazer uma avaliação conclusiva (Mirowski, 1989).

3 "Contudo, as concepções biológicas são mais complexas que as da Mecânica: um volume de Fundamentos deve dar por isso um lugar relativamente grande às analogias mecânicas” (Marshall, V. I, 1982: 10). Embora não fosse um dos defensores mais ardorosos da inspiração na física - e fosse algumas vezes ambíguo (ou mesmo contraditório) - é difícil duvidar, como apontou Mirowski (1989), que para Marshall a referência principal para a economia fosse a física - não apenas a mecânica (ver a seguir) - e não a biologia (Georgescu-Roegen, 1977). Segundo Georgescu-Roegen, o célebre conselho de Marshall, para quem "[a] Meca do economista está antes na Biologia econômica do que na Dinâmica econômica", não foi seguido também pelo próprio autor (Georgescu-Roegen, 1977; ênfase acrescentada).
} 
cionar muitos dos mesmos formalismos matemáticos" (Mirowski, 1989: 4) ${ }^{4}$. Segundo este mesmo autor, desde o começo do século passado, os economistas deixaram de se inspirar na física de maneira tão direta.

Já a abordagem do tempo em economia talvez seja um exemplo conspícuo da adoção radical e particularmente longeva do paradigma determinista (Georgescu-Roegen, 1988). Embora este último já não fosse o padrão dominante da abordagem do tempo em várias disciplinas cientificas no século XX (Gould, 1991a e b; Prigogine, 1996; Mayr, 2008; Pomian, 1993a).

De fato, em algumas ciências e disciplinas, como na geologia, na biologia e na termodinâmica, a concepção do tempo como sendo reversível, simétrico e plenamente previsível fora abandonada ainda no século XIX (Prigogine, 1996; Coveney e Highfield, 1993; Mayr, 2008; Georgescu-Roegen, 1977).

Ao longo do século XX, a chamada flecha (ou seta) do tempo - a interpretação do tempo como sendo linear, cumulativo e irreversível - tem se difundido até mesmo entre as ciências naturais (como na cosmologia, na astronomia, na meteorologia, em áreas da química e na termodinâmica, na física) e se tornou mesmo hegemônica nas ciências da vida (biologia, paleontologia, ecologia, psicologia, botânica etc.) (Gould, 1991a e b; Prigogine, 1996; Mayr, 2008; Pomian, 1993a; Popper, 1957). Desnecessário lembrar que nas ciências sociais e entre os historiadores, a concepção da flecha do tempo está há bastante tempo bem estabelecida (Elias, 1984; Braudel, 1998; Hobsbawn, 2014).

Por outro lado, o desenvolvimento de alguns novos paradigmas científicos como o dos sistemas dinâmicos instáveis (Prigogine, 1996; Coveney e Highfield, 1993) , o da auto-organização (Silverberg, 1988; Kauffman, 1993) o da complexidade (Kauffman, 1995; Prado, 2014) e o do caos (Ruelle, 1993; Prigogine, 2002) -, com aplicação bastante diversificada em várias disciplinas científicas e que incorporam a concepção da flecha do tempo, tem contribuído bastante para aumentar o interesse e ajudar a difundir a interpretação não determinista do tempo.

O objetivo deste artigo é apresentar as principais contribuições heterodoxas (não deterministas) para a abordagem do tempo (ver a seguir), em economia, e contrapô-las ao enfoque dominante (determinista). Adicionalmente, busca-se contribuir para a compreensão dos motivos pelos quais a abordagem determinista do tempo segue sendo predominante - e talvez hegemônica - entre os economistas, não obstante o fato de que o enfoque alternativo, não determinista, se mostre mais adequado ao seu objeto - os diversos processos econômicos - e venha ganhando bastante atenção e importância numa ampla gama de disciplinas científicas. Sem ter a pretensão de oferecer uma resposta cabal ou definitiva para esta importante e intrincada questão, este artigo procura, entretanto, avançar uma hipótese explicativa para esta situação intrigante e paradoxal.

Este artigo está estruturado da seguinte forma: a esta introdução seguem-se

4 “[...] [P]ermanece o fato que Marshall tornou a metáfora proto de energética segura e tranquilizadora para uma audiência inglesa vitoriana (Mirowski, 1989, p. 263). 
mais cinco intens. O segundo item, a seguir, tratou do enfoque paradoxal do tempo na economia. No terceiro item procurou-se fazer uma contextualização das principais contribuições dos economistas no século XX - especificamente, Marshall, Keynes e Myrdal -, para a abordagem não determinista do tempo. Nos quarto e quinto itens buscou-se apresentar e discutir as concepções sobre o tempo, em economia, de dois dos maiores especialistas neste importante tema: G. L. S. Shackle e Sir J. Hicks. No último item foram feitas, como de praxe, as considerações finais.

\section{A ABORDAGEM PARADOXAL DO TEMPO EM ECONOMIA ${ }^{5}$}

Tendo em vista as considerações anteriores, é no mínimo paradoxal que, em economia, o enfoque determinista do tempo ainda seja amplamente dominante. Paradoxal porque esta abordagem do tempo é visivelmente não apropriada ao seu objeto (ver a seguir), que é constituído pelos múltiplos e diversificados processos econômicos (Georgecu-Roegen, 1988). Quanto à utilização da terminologia determinista para o tempo - que resulta da aplicação da concepção determinista, também, ao próprio tempo -, ela foi proposta por Prigogine (1996), para caracterizar a visão ainda majoritária (tradicional) do tempo na Física (Whitrow, 2005).

Analogamente, a denominação tempo determinista parece ser uma boa caracterização da abordagem amplamente dominante em economia, segundo, por exemplo, as interpretações de Shackle (1990, 1976 e 1969), de Hicks (1979 e 1972), de O’Driscoll e Rizzo (2002) e de Davidson (2011). De fato, esta concepção do tempo determinista parece ser compatível, também, com as características do tempo em condições ergódicas, segundo a abordagem proposta por Davidson (2011).

Segundo a concepção determinista, o tempo seria caracterizado pela reversibilidade, pela simetria e pela perfeita previsibilidade. Esta interpretação torna-se particularmente surpreendente quando se leva em conta que aquelas características mencionadas não se mostram adequadas à maioria dos processos econômicos aos quais deveriam ser aplicadas.

Ademais, a surpresa é reforçada pelas circunstâncias de que o paradigma evolucionário (a flecha da vida) é hegemônico nas ciências da vida (Mayr, 2001 e 2008; Gould, 1987a e b) e que a perspectiva de que a história importa (flecha da história) está também amplamente consolidada nas ciências sociais (Elias, 1984; Braudel, 1996; Hobsbawn, 2014). Da mesma forma, também é significativo que até mesmo a física - seja através da segunda lei da termodinâmica (a flecha termodinâmica), seja através da teoria do big-bang (a flecha cosmológica) - já não se encontra mais totalmente imune à irreversibilidade da passagem do tempo e tão adepta da con-

\footnotetext{
${ }^{5} \mathrm{O}$ adjetivo paradoxal está sendo utilizado aqui sem nenhuma conotação filosófica ou mesmo lógica. Ele está sendo empregado com o sentido que habitualmente aparece nos dicionários: que encerra paradoxo - "conceito que é ou parece contrário ao comum; contrassenso, absurdo, disparate [...]" (Holanda Ferreira, 1975, p. 1032). Para uma abordagem do paradoxo do tempo, em termos gerais, que tem semelhanças com a que é feita aqui, ver Prigogine (2002).
} 
cepção da perfeita previsibilidade - vigência do axioma ergódico (Prigogine, 1996; Coveney e Highfield, 1993; Pomian, 1993a; Davies, 1995).

Mas o paradoxal enfoque do tempo em economia parece ter decorrido mais da manutenção tardia do paradigma determinista - e da adoção generalizada dos modelos de equilíbrio - do que da distância que a economia, também, tem mantido das outras concepções científicas (e das suas respectivas abordagens do tempo), particularmente daquelas das ciências mais próximas - ciências sociais e da vida (Georgescou-Roegen, 1988 e 1977; Klein, 1977; Pomian, 1993a).

Neste processo, as concepções econômicas (os modelos) de equilíbrio ${ }^{6}$ geral, parcial - de curto e longo prazo $^{7}$-, intertemporal (Milgate, 1987), temporário (Hansson,1991), estacionário (ou estático) (Panico e Petri, 2008) e as suas respectivas noções de tempo - como processo intemporal (ou atemporal), instantâneo, mecânico (ou de mecanismo), ou estritamente lógico (Robinson, 1988; Shackle, 1976) - têm funcionado, ao que tudo indica, como os canais principais de transmissão/manutenção das concepções deterministas do tempo, originárias da mecânica clássica, que têm prevalecido entre os economistas até hoje (Shackle, 1969 e 1976; Robinson, 1979 e 1988; Hicks, 1972 e 1979).

Isto é, depois da influência inicial da física (Mirowski, 1989), a explicação da predominância da abordagem determinista do tempo na economia deve ser procurada no seu próprio desenvolvimento interno, principalmente na introdução e difusão dos modelos de equilíbrio (e suas variantes), particularmente entre os economistas do mainstream.

Como se sabe, os modelos de equilíbrio ${ }^{8}$ pressupõem que a escolha da ação seja baseada no conhecimento adequado (perfeito). O conhecimento perfeito suposto no equilíbrio é, por sua vez, incompatível com um enfoque não determinista do tempo. E, pelo contrário, o equilíbrio exige uma abordagem determinista do tempo - caracterizado como sendo reversível, simétrico e perfeitamente previsível, como já destacado -, sem a qual não se preservaria as condições para o suposto conhecimento perfeito das circunstâncias que afetariam os resultados relevantes (Shackle, 1976 e 1991).

Sob as supostas condições de previsibilidade perfeita, os eventos seriam completamente determinados por causas anteriores (antecedentes) e não seriam afetados por fatores aleatórios. Ou seja, se o futuro econômico for plenamente previsí-

\footnotetext{
${ }^{6}$ Como se sabe, os modelos de equilíbrio da economia também foram inspiradas/emprestadas na/da física. "Igual a 'estática' e a 'dinâmica', o 'equilíbrio' é um empréstimo da mecânica matemática"[...] (Hicks, 1989, p. 18). Para uma discussão dos modelos de equilíbrio em economia, ver Hicks (1989) e Shackle (1969 e 1976). Para uma interessante comparação entre as concepções de equilíbrio na economia e na física, ver Mirowski (1989).

${ }^{7}$ Além das influentes noções de equilíbrio de curto e longo prazo, Marshall formulou também a noção de equilíbrio temporário, relativo ao período de mercado (Milgate, 1987).

${ }^{8}$ Adota-se aqui a perspectiva, compartilhada, também, por Shackle (1976, 1991 e 1969), Hicks (1989) e Hansson (1991), de que os modelos de equilíbrio têm características gerais que comportam, entretanto, algumas variantes.
} 
vel não haveria, por definição, inovação nem algum tipo de novidade e qualquer alteração seria completamente previsível. Negar a existência de inovações e de novidades talvez seja a maior dificuldade dos economistas que assumem que o tempo - o futuro - é totalmente previsível (ver abaixo os quarto e quinto itens) (Keynes, 1978 e 1983; Schumpeter, 1984, Hicks, 1976; Shackle, 1976 ; Knight, 1972; Davidson, 2011; Popper, 1982).

Não é mera coincidência, por outro lado, que não muitos economistas defendem a preponderância e/ou mesmo a relevância de processos irreversíveis (Shackle, 1976 e1969; Hicks, 1976 e 1989; Georgescu-Roegen,1977; Robinson 1979 e 1988). Esta situação tem prevalecido apesar da dificuldade de se postular, realisticamente, a reversibilidade da maior parte dos processos econômicos e da difundida percepção, já apontada, que a maioria dos processos histórico-sociais, biológicos e até mesmo alguns processos físicos - termodinâmico e cosmológico - são igualmente irreversíveis (Schorödinger, 1977; Popper, 1957 e 1967; Pomian, 1993a).

Admitindo-se, ademais, uma hipotética simetria do tempo, o futuro se tornaria idêntico ao passado e, além disso, nenhuma novidade ou mudança poderia ocorrer (Shackle, 1976; Hicks, 1976; Davidson, 2011). No mundo físico a simetria do tempo (em certos processos físicos) significa que o sentido do tempo - para a frente ou para trás; passado ou futuro - é indiferente (Amsterdamski, 1993). O exemplo do pêndulo é clássico. Difícil imaginar, entretanto, processos histórico - sociais, econômicos ${ }^{9}$ - que também são sociais e históricos -, ou mesmo biológicos que sejam fundamentalmente simétricos.

Com base no que foi apresentado acima, é possível classificar as diferentes abordagens do tempo em economia em dois grupos principais, cada um dos quais comportando subclassificações. $\mathrm{O}$ tempo determinista - que tem prevalecido entre os economistas, principalmente do mainstream - é o tempo do equilíbrio, tanto geral quanto parcial, e é também, em decorrência, o tempo do suposto conhecimento perfeito, da reversibilidade e da pretendida previsibilidade perfeita (Shackle, 1991, 1969 e 1976).

Tendo em conta que o tempo não determinista tem sido caracterizado como fonte de novidade, de mudança, de incerteza, de expectativas e de irreversibilidade ${ }^{10}$, é necessário reconhecer que existe uma ampla, profunda e irreconciliável oposição entre as duas concepções do tempo (Shackle, 1969, 1976 e 1991). É indispensável reconhecer, também, que ocorre, de outra parte, o que parece ser uma incompatibilidade incontornável entre a concepção de tempo não determinista e os modelos de equilíbrio ${ }^{11}$. Ou seja, uma hipotética substituição da concepção determinista do

\footnotetext{
${ }^{9}$ Cabe ressaltar que mesmo os processos econômicos cíclicos não são rigorosamente simétricos (Pomian, 1993b).

${ }^{10} \mathrm{E}$ também como sendo assimétrico, não passível de perfeita previsão e diacrônico - com a distinção entre o passado, o presente e o futuro.

${ }^{11} \mathrm{Em}$ uma formulação que apresenta semelhanças com esta apresentada aqui, Shackle (1976)
} 
tempo pela não determinista esbarraria no formidável obstáculo decorrente do arraigado apego da maior parte dos economistas aos modelos de equilíbrio.

Não obstante as considerações anteriores, alguém poderia aventar a hipótese de que a abordagem paradoxal do tempo em economia - isto é, a prevalência de uma interpretação não apropriada ao seu objeto - seja apenas um anacronismo, resultado de um comportamento costumeiro que se mantém, fundamentalmente, por força do hábito.

Tal interpretação conflita, totalmente, com a argumentação desenvolvida neste artigo. Da perspectiva aqui adotada, o predomínio da abordagem determinista do tempo é, por assim dizer, fundamentalmente um subproduto - ou um efeito colateral - indissociável dos modelos de equilíbrio. Assim sendo, torna-se claro porque não é possível, então, postular-se que a dominância do enfoque determinista do tempo, em economia, possa ser considerada como apenas um anacronismo.

A compreensão da dominância da abordagem paradoxal do tempo em economia talvez possa ajudar, também, a entender, em alguma medida, por que a maior parte dos economistas continua considerando a economia como uma ciência não-histórica e/ou determinista (ver abaixo) (Shackle, 1976; Hicks, 1972 e 1979).

\section{AS PRINCIPAIS CONTRIBUIÇÕES DOS ECONOMISTAS DO SÉCULO XX PARA A ABORDAGEM NÃO DETERMINISTA DO TEMPO}

O propósito deste item é de apenas contextualizar as principais contribuições do século XX (e os seus respectivos autores) relacionadas à abordagem não convencional (não determinista) do tempo, em economia ${ }^{12}$.

\section{Marshall e a análise dos períodos}

Como vimos na epígrafe e na nota $\mathrm{n}^{\circ} 2$ deste artigo, parece haver indicações consistentes de que Marshall foi um autor mais preocupado com a questão do tempo - e que lhe tenha dando uma interpretação bem diferente - do que os seus pares marginalistas ${ }^{13}$ (Schumpeter, 1958 e 1994; Shackle, 1969 e 1976; Keynes, 1972; Georgecu-Roegen, 1988 e 1977). Igualmente, os indícios são de que ele recuperou, de certa forma e em certa medida, a importância que o tema do tempo

\footnotetext{
argumentou que o tempo (não determinista) está em oposição à razão (racionalidade maximizadora). (ver o item quarto, abaixo).

${ }^{12}$ Em razão da natureza do item, do fato de que os conceitos e as noções aqui apresentados serem, em geral, bastante conhecidos e da limitação de espaço, optou-se por não discutir neste item as noções e os conceitos abordados aqui.

${ }^{13}$ Um reforço adicional desta inferência resulta da consulta ao conjunto da bibliografia utilizada na elaboração deste artigo. Nenhum outro autor da sua geração recebeu, nem remotamente, tanta atenção quanto à dispensada a Marshall, especialmente em relação ao tema do tempo, pelo conjunto dos autores mencionados neste artigo.
} 
teve para os clássicos. Mas como veremos a seguir, tal avaliação é, provavelmente, demasiado otimista, não obstante o fato de que o grande autor marginalista inglês tenha, de fato, se ocupado do tema e tenha lhe dedicado atenção e ideias fecundas.

Como se sabe, Marshall formulou três conceitos diretamente relacionados ao tempo: os conceitos de períodos de mercado, de curto e de longo prazo (também conhecido como análise de períodos). Ademais, ele utilizou amplamente e deu novo status a uma concepção antiga - a chamada cláusula de coeterisparibus - que, de certa forma, está também relacionada ao tempo.

Os conceitos de curto e longo prazos ${ }^{14}$ lograram grande impacto na literatura econômica e foram os motivos principais da grande repercussão que os Princípios e o seu autor obtiveram junto aos seus pares (Whitaker, 1996; Shackle, 1969). "A introdução explícita do elemento tempo como um fator na análise econômica é principalmente devida a Marshall” (Keynes, 1972, p. 206). Não obstante, na página seguinte do influente ensaio biográfico que escreveu sobre o seu ex-professor, Keynes observou que aquele é o assunto em que "a análise de Marshall é menos completa e satisfatória, e onde permanece muita coisa para ser feita” (Keynes, 1972, p. 207; Schumpeter, 1994).

Apesar da referida repercussão, os dois conceitos têm sofrido com a restrição de serem utilizados - muito frequentemente, inclusive pelo próprio Marshall (V. II, 1985) - em simultâneo ao conceito de concorrência perfeita, ao modelo de equilíbrio parcial (estático) e à concepção de coeterisparibus (Shackle, 1976; Hicks, 1989). Tal combinação, altamente restritiva, limitou as potencialidades dos conceitos de análise de períodos e, por exemplo, as suas possibilidades de tratarem apropriadamente do tempo - possibilidades que são, de fato, maiores no caso do conceito de longo prazo.

Com base nos autores aqui consultados (especialmente, em Keynes, Hicks e Shackle), talvez não seja exagerado afirmar que a combinação dos conceitos de concorrência perfeita, do modelo de equilíbrio estático (parcial) e da cláusula de coeterisparibus, realizada por Marshall, resultou numa barreira praticamente intransponível, inviabilizando que o tempo, a mudança e a história tivessem, de fato, uma abordagem apropriada e realista em seus trabalhos. Tal resultado ocorreu apesar das contribuições, inegavelmente relevantes, relativas à análise de períodos efetuada pelo autor e das suas reiteradas afirmações quanto à importância do tempo em economia.

\section{O Tempo em Keynes}

Ao adotar os conceitos de incerteza e de expectativas e ao associá-los a vários outros conceitos importantes da sua teoria - como, por exemplo, demanda efetiva,

\footnotetext{
${ }^{14}$ Está-se desconsiderando, por questão de espaço, o conceito de período de mercado porque este último não obteve uma aceitação tão ampla quanto os outros dois conceitos. Embora se reconheça, por exemplo, que o conceito de período de mercado seja relevante na precificação dos ativos, como foi oportunamente lembrado por um dos pareceristas.
} 
eficiência marginal do capital e preferência pela liquidez -, Keynes deu novo sentido ao futuro e ao presente em economia e, por extensão, ao próprio tempo (Shackle, 1976, 1969 e 1991).

No famoso artigo publicado em 1937, ao procurar esclarecer o sentido que ele atribuiu à incerteza, Keynes colocou a questão nos seguintes termos: “[d]esejo explicar que por conhecimento 'incerto' não pretendo apenas distinguir o que é conhecido como certo, do que apenas é provável. Neste sentido, o jogo da roleta não está sujeito à incerteza; nem sequer a possibilidade de se ganhar na loteria. [...] O sentido em que estou usando o termo é aquele segundo o qual a perspectiva de uma guerra europeia é incerta. [...] Ou [também é incerta] a obsolescência de uma nova invenção"(Keynes, 1978, p. 171).

No capítulo 5 da Teoria Geral, ao abordar a questão das expectativas, Keynes tratou do assunto da seguinte forma: as "[...] expectativas, das quais dependem as decisões da atividade econômica, dividem-se em dois grupos, havendo certos indivíduos ou firmas especializadas na elaboração de expectativas do primeiro tipo e outras na elaboração do segundo.[...] Chamaremos às primeiras expectativas a curto prazo e às segundas expectativas a longo prazo"(Keynes, 1983, p. 43; itálicos originais).

A importância e o destaque dado por Keynes ao tempo foi além da adoção dos conceitos de incerteza e de expectativas e dos respectivos desdobramentos relacionados à incorporação destes últimos aos vários outros conceitos keynesianos importantes. De fato, Keynes destacou a importância do tempo em economia em mais de um lugar. Na Teoria Geral, ele também enfatizou, por exemplo, a relevância do tempo no processo produtivo. No artigo de 1937, Keynes deu ênfase, por outro lado, à relação entre o tempo e o processo de valorização da riqueza.

Não obstante a importância e o destaque dado ao tempo por Keynes na Teoria Geral e em alguns dos seus artigos posteriores, não há em nenhum dos seus trabalhos - nem mesmo no artigo de 1937 (A Teoria Geral do Emprego) - uma abordagem ampla e sistemática da questão do tempo em economia (Shackle, 1976). Esta importante lacuna só veio a ser, parcialmente, preenchida, do ponto de vista deste autor, com as publicações dos trabalhos de Shackle sobre o tempo (ver abaixo).

\section{Myrdal e a distinção ex ante e ex post ${ }^{15}$}

Com a criação da distinção conceitual entre ex ante e ex post, Gunnar Myrdal talvez tenha feito a maior contribuição individual da famosa escola de economia

\footnotetext{
${ }^{15}$ Embora exista uma certa polêmica sobre a verdadeira autoria da concepção ex ante e ex post, ela é, na maior parte das vezes, atribuída a Gunnar Myrdal. A citação a seguir, que foi extraída do verbete ex ante e ex post do reconhecido dicionário de economia da Palgrave, parece ser um bom indicador da situação. "A terminologia [ex ante e ex post] foi introduzida em teoria macroeconômica, especialmente com respeito à relação investimento-poupança, por Gunnar Myrdal $(1933,1939)$ e clarificado e incorporado na análise de períodos ou de sequência por Erik Lindahl (1934, 1939b)[...]. Uma mais coerente análise desses conceitos [ex ante eex post] foi dada na dissertação de Myrdal sobre expectativas e mudanças de preços (1927, pp. 67f.) [...]”(Steiger, 1987, pp. 199-200).
} 
de Estocolmo dos anos 1930 (Hansson, 1991). "O primeiro método de cálculo é 'o registro' acerca do que realmente aconteceu durante um período completo, o segundo modo de cálculo é um cálculo empresarial fundado na estimação do que vai acontecer no futuro" (Myrdal, 1939, p. 54). As antecipações ex ante até podem ser a força guia do processo dinâmico, mas os resultados ex post ainda têm um papel, uma vez que "como base para os cálculos ex ante, as experiências gravadas ex post podem regularmente serem decisivas" (Myrdal, 1939, p. 55).

A ausência da separação entre as antecipações e os resultados era motivo para inúmeros mal-entendidos. Por este motivo, a distinção entre os conceitos ex ante e ex post, implementada por Myrdal - além de lançar luz sobre a questão específica da natureza do tempo -, também ajudou a esclarecer, em boa medida, as discussões a respeito dos investimentos, da poupança e da renda, bem como dos efeitos destes conceitos sobre os preços (Streeten, 1987).

Ao longo do processo que o levou a conceber a distinção entre ex ante e ex post, Myrdal fez mais do que apenas entender o papel fundamental das expectativas e das consequências radicais da sua incerteza (Shackle, 1991). "Ao introduzir as expectativas na análise do processo econômico ele fez uma grande contribuição para liberar a economia da teoria estática, na qual o futuro é como o passado, e para pavimentar o caminho para a dinâmica, em que o tempo, incerto e com expectativas entra de uma maneira essencial” (Streeten, 1987, p. 581).

Como foi apropriadamente destacado por Shackle (1991), ao afirmar que o passado e o futuro são eventos distintos, [...]"Myrdal libertou a teoria econômica da premissa tácita e limitadora de que a economia se move como os planetas, em caminhos conhecidos cada qual na sua totalidade, independentemente do ponto no qual um dado planeta se encontra no momento em que estamos calculando sua orbita. O futuro não é conhecido para aqueles cujas decisões, no seu efeito conjunto e na sua interação, o determinam" (Shackle, 1991, p. 114; itálico acrescentado).

\section{SHACKLE E AS VÁRIAS FACES DO TEMPO}

Shackle foi, provavelmente, o economista que mais escreveu sobre o tempo ${ }^{16}$. Segundo Georgescu-Roegen (1994), influente economista e que também se ocupou deste tema, G. Shackle, A. Whitehead e H. Bergson foram os grandes pensadores do tempo em nossa era. Assim sendo, não parece exagerado afirmar que Shackle foi uma das maiores autoridades em relação ao tempo entre os economistas ${ }^{17}$.

\footnotetext{
${ }^{16}$ Contam-se entre os trabalhos escritos pelo autor pelo menos cinco livros (e alguns artigos) que tratam direta e explicitamente de tempo: Time in Economics (1958); Decisión, Orden y Tiempo en las Actividades Humanas (1966); Um Esquema de Teoria Econômica (1969); Epstemica y Economia (1976) e Time, Expectations and Uncertainty in Economics (1990). Dentre os artigos, pode-se destacar "Time and Choice" (1976).

${ }^{17}$ Hicks, que também será objeto deste artigo, foi outro grande autor que se ocupou do tema do tempo,
} 
Diferentemente da maioria dos autores que, de alguma forma, trataram do tempo em economia, Shackle abordou o tema de maneira ampla e sistemática. Em Um Esquema de Teoria Econômica (1969), o assunto é discutido na introdução e no item VII. Neste item são feitas comparações (e comentários críticos) entre diversas abordagens do tempo elaboradas por vários autores relevantes: Walras; Leontief; Harrod-Hicks; Teoria Austríaca; Marshall; os neowicksellianos (Lindahl/Myrdal) e Keynes.

A partir dos vários enfoques do tempo desenvolvidos pelos referidos autores, Shackle (1969) propôs uma tipologia do tempo em economia baseada em quatro concepções: o tempo mecânico - inspirado nas interpretações de Harold e de Hicks-; o tempo evolucionário - associado à visão de Marshall -; o tempo expectacional - vinculado às ideias de Keynes, de Myrdal/Lindahl e do próprio autor e dos modelos intemporais baseados nas concepções de Walras e de Leontief (Shackle, 1969; Carvalho, 1983) ${ }^{18}$.

Em Epistemica y Economia, o tempo, e as suas muitas faces, é enfocado de vários pontos de vista - e em vários capítulos ${ }^{19}$. Dentre as várias questões abordadas pelo autor (ver a seguir) destacam-se a relacionada à oposição entre a razão (racionalidade maximizadora) e o tempo (não determinista) e a relativa ao problema do diacronismo, no qual se inclui a importante discussão da separação conceitual entre passado, presente e futuro. Muito embora possa ser considerada intuitiva para alguns, tal distinção não parece ser nada trivial para os economistas, a se julgar pelo simples fato de que um número não muito amplo destes adota a referida separação e as reais consequências da mesma (Shackle, 1976 e 1966).

A razão supõe o pleno conhecimento, mas o tempo (não determinista) introduz a possibilidade da novidade, da mudança e da incerteza. "O tempo é a negação da onipotência da razão". [...] "Assim, pois, a razão e o tempo parecem estar em desacordo, porque se pede à razão o significado das premissas que sempre estão parcialmente não enunciadas" (Shackle, 1976, pp. 49 e 47). Diante deste dilema parece haver dois grupos de estratégias principais e opostas. Do ponto de vista da razão, a saída tem sido negar o tempo e/ou tentar assimilá-lo ao espaço. Da perspectiva do tempo (não determinista) é necessário admitir que a razão não é onipotente e que, portanto, não existe conhecimento pleno em presença do tempo, caracterizado por novidade, mudança e incerteza (Shackle, 1976).

"O sujeito pode escolher a sua posição no espaço, mas não pode [escolher] sua posição no tempo" (Shackle, 1966, p. 57). Não obstante, parece que o "[n]osso

especialmente nos últimos anos da sua vida. Embora não tenha escrito tanto quanto Shackle sobre o assunto, Hicks contribuiu a ponto de ser considerado também uma autoridade no tema.

${ }^{18}$ Para uma apresentação equilibrada e uma análise crítica pertinente desta tipologia do tempo, proposta por Shackle (1969), ver Carvalho (1983).

${ }^{19}$ Em Decisión, Orden y Tiempo en las Actividades Humanas (1966), a discussão do tempo é menos extensa e é, em boa medida, complementar à que foi elaborada posteriormente em Epistemica y Economia (1976). 
modo de pensamento nos obriga a assimilar o tempo, em uma de suas acepções, à expressão espaço com sucessão, para que possamos ordenar o registro adequadamente em nossos pensamentos" (Shackle, 1976, p. 299). Por certo, a concepção de que existe um passado, um presente e um futuro, não implica em assimilar o tempo ao espaço, mas talvez signifique admitir que "[o] tempo como espaço com sucessão é quiçá um artifício do pensamento, mas é um artifício indispensável” (Shackle, 1976 , p. 305).

[...] [O] presente é uma concepção binocular que encerra uma comparação de etapas ou de pontos de vista. Assim, pois, no eixo calendário, o presente tem que ocupar um segmento breve. [...] [Q]uão largo é o presente. [...] [S]e o presente é solitário, [...] que significa o resto do eixo-calendário?"(Shackle, 1976, pp. 298-99). Mas o conceito de momento-presente - que não se confunde com instante presente, pois aquele tem uma certa duração - é tal que envolve e abarca um momento-sucessor, que de sua parte tem também um momento-sucessor e assim por diante.

Em conjunto, os momentos-sucessores configurarão o futuro - que não está predeterminado nem pronto para ser descoberto - mas que deve ser criado, com as novidades, as mudanças e apesar das incertezas (Shackle, 1966). Uma tal concepção de futuro significa, entre outras coisas, o reconhecimento de "que não podemos construir modelos que exibam o curso [futuro] da história de uma sociedade, nem se quer ao longo de um espaço limitado de tempo"(Shackle, 1976, pp. 48-49).

Diferentemente do presente e à semelhança do futuro, o passado não pode ser concebido como um momento. Talvez possa ser pensado como uma sucessão de momentos, ou como um grupo ou ainda como um período. Assim como o futuro, o passado também não tem a mesma atualidade do presente. Embora seja discutível que o passado não tenha nenhuma atualidade, afinal de contas pode-se argumentar que parte do presente é o passado que, em certa medida, transformou-se (e sobreviveu) (Shackle, 1966).

Tipicamente um processo diacrônico, o ciclo econômico e a sua dimensão de tempo também foram objeto de análise do autor. Sem pretender aprofundar a discussão dos ciclos, é possível dizer, sinteticamente, que eles são caracterizados por processos cumulativos e por defasagens temporais. A ocorrência das defasagens temporais e os próprios ciclos econômicos nos alertam para mais uma outra importante característica do tempo em economia: muito raramente os processos econômicos são sincrônicos - porque eles não são instantâneos, porque têm duração diferente (levam tempo distintos) e porque alguns só ocorrem depois que outros já tenham ocorrido - ; as diferentes e sucessivas fases do ciclo econômico são um bom exemplo deste último caso (Pomian, 1993b; Shackle, 1976).

Muito embora seja, provavelmente, o mais conhecido de Shackle, o conceito de decisão crucial (ou experimento crucial) não será objeto deste artigo porque, a rigor, não é um conceito que concerne especificamente ao tempo, embora tenha claramente relação com ele. De fato, decisão crucial é um conceito do âmbito da 
tomada de decisão, temática da qual este autor também se ocupou ampla e profundamente $^{20}$ (Shackle 1966; Carvalho, 1983).

\section{HICKS E A IRREVERSIBILIDADE DO TEMPO}

Ganhador do Prêmio Nobel em 1973, a trajetória de J. Hicks é, em geral, bem conhecida. O que talvez seja menos sabido é que sua carreira sofreu uma importante inflexão em meados dos anos 1960. Quanto ao tema deste artigo, a mudança de Hicks se deu claramente no livro Uma Teoria de História Econômica (1972), no qual o autor explicita uma nova e distinta visão da história e também do tempo ${ }^{21}$. Segundo o autor, é necessário examinar os registros históricos que permanecem por trás de nós, para nos certificarmos que o nosso procedimento lógico não toma um caminho que conflita com os fatos mais visíveis e importantes. "Mas não poderemos - como uma teoria determinística pensaria poder fazer - extrapolar o futuro; tudo o que poderemos fazer, tudo o que o economista poderá fazer, é especular sobre coisas que mais ou menos provavelmente podem acontecer. $\mathrm{E}$ ainda tal coisa será deixada de lado quase sempre” (Hicks, 1972, p. 15; itálico acrescentado).

Embora Hicks não tenha escrito diretamente muito sobre o tempo, como mencionado anteriormente, ele o fez, de maneira mais intensa (e significativa), na parte final de sua carreira. A importância e a relativa frequência desta contribuição é que justificaram a inclusão de Hicks neste artigo, entre os economistas que mais contribuíram para a compreensão do tempo na economia, no século XX.

Em Some Questions of Time in Economics - originalmente uma palestra em honra ao Prof. Georgescu-Roegen e que, posteriormente, foi publicada em livro -, o autor defendeu o que chamou de o princípio da irreversibilidade do tempo. "No espaço nos podemos nos mover numa ou em qualquer direção; mas o tempo apenas vai em frente, nunca vai para trás” (Hicks, 1976, p. 283; Hicks, 1989). Ainda segundo o autor, uma das mais importantes decorrências da irreversibilidade do tempo é que o passado e o futuro são diferentes. "O conhecimento que nós temos, ou podemos ter, do passado é diferente em espécie daquele que nos podemos conhecer do futuro [...]" (Hicks, 1976: 283).

Em Perspectivas Econômicas (1978), Hicks apontou, também (e apropriadamente), para a insuficiência das séries temporais com relação ao tratamento adequado do tempo. "Procurei manter meu pensamento mais seguro acerca do tempo, preocupei-me com processos, mas não apenas com isso. Não é suficiente pensar em

\footnotetext{
${ }^{20}$ Situações bastante semelhantes ocorrem, também, com o famoso princípio de causação cumulativa de Myrdal e com o conceito do multiplicador de Keynes e Kahn, razão pela qual estes conceitos não foram, também, abordados nos subitens relativos ao autor sueco (3.3) e a Keynes (3.2) neste artigo (Streeten, 1987; Shakle, 1976 e 1991).

${ }^{21}$ Estas ideias voltam a aparecer em Causality in Economics, onde Hicks aborda também a sua nova perspectiva da relação entre economia e história e delas com o tempo (Hicks, 1979).
} 
termos de séries temporais. As unidades de tempo devem estar ligadas entre si e ligadas no tempo, o futuro tornando-se presente e o presente tornando-se passado, à medida que o tempo passa". Segundo o autor, deve-se imaginar que, em tal modelo, as pessoas não sabem o que irá acontecer, [...] "e que sabem que não sabem exatamente o que irá acontecer. Como na História!” (Hicks, 1978, p. 9; itálico acrescentado).

Já em Métodos de Economia Dinâmica, embora a questão do tempo também seja relevante, ela não é, de fato, central e o autor poucas vezes a aborda de maneira tão direta, como no trecho a seguir. "O processo ocorre no tempo; o tempo se dirige em uma só direção. Deve-se distinguir o passado do futuro. [...]”. O passado, sempre que seja importante, terá sido incorporado nos resultados das decisões tomadas anteriormente. [...] "Mas o futuro também é importante [...]. Devemos introduzir expectativas do futuro, de um futuro depois do tempo $t[\ldots]$ ”. Mas “[a] s expectativas podem ou não serem certas"[...] (Hicks, 1989, p. 26; itálico acrescentado).

Em Causality in Economics, Hicks aborda, como mencionado antes, as relações entre a história e a economia e de ambas com o tempo. "Se ele é um historiador puro, ele pode ir para sua data no passado - o seu 'período' - e permanecer lá” [...]. Mas para o economista, que está ciente de que está estudando o passado em razão do presente, a visão dupla é uma necessidade que se impõe. [...] "Ele sempre está sob a necessidade de olhar o passado de duas maneiras, a partir do seu ponto de vista e dele próprio; ou, como ele aprendeu a dizer, ex ante e ex post" (Hicks, 1979, p. 6).

Cabe destacar, por fim, que vários trabalhos do autor têm o tempo como questão importante, embora ele não seja abordado de forma tão explícita como nos trabalhos aqui comentados. Na situação em que o tempo é enfocado de maneira mais implícita encontram se, por exemplo, os livros: Valor e Capital (1939); Theory of the Trade Cycle (1950); Capital e Crescimento (1965) e ate mesmo Capital e Tempo (1973). Embora também tenha formulado uma noção (ou conceito) diretamente vinculada ao tempo - a semana (Valor e Capital, 1939) - , Hicks foi incluído neste artigo pela sua importantíssima contribuição à discussão recente sobre o tempo, até porque a sua noção "a semana" não logrou maior repercussão entre os seus pares ${ }^{22}$.

\section{CONSIDERAÇÕES FINAIS}

A partir do que foi apresentado e discutido neste artigo, é possível classificar os diferentes enfoques do tempo em economia em dois grupos principais: o tempo determinista (dominante) e o não determinista (heterodoxo). Em razão das carac-

\footnotetext{
${ }^{22}$ Para uma autocrítica do autor sobre a noção de "semana”, ver Hicks (1978).
} 
terísticas de cada um deles é necessário constatar que persiste uma oposição incontornável entre as duas abordagens, em economia, do tempo.

Uma vez que não parece muito razoável postular-se que a predominância da abordagem determinista do tempo se explique, apenas ou principalmente, pelos seus atributos internos - como se viu, tal abordagem não tem se mostrado muito apropriada aos processos econômicos - , a explicação mais plausível para a adoção generalizada deste enfoque do tempo, pelos economistas, parece estar intrinsecamente vinculada, como já apontado, à utilização também muito frequente dos modelos de equilíbrio geral e parcial.

Estas considerações finais talvez devam se encerrar com alguns esclarecimentos sobre os critérios que levaram à escolha dos cinco autores (Marshall, Keynes, Myrdal, Shackle e Hicks) que foram abordados neste artigo. Além da óbvia restrição de espaço, que limitou a escolha a um número relativamente reduzido de autores, adotou-se como critérios que o autor tenha feito uma importantíssima contribuição direta ou indireta - sem formular conceitos relacionados diretamente ao tempo - à abordagem heterodoxa do tempo ou, ainda, tenha desempenhado um papel de grande destaque na sua discussão e esclarecimento. No primeiro critério se enquadram Marshall e Myrdal. Keynes atende ao segundo requisito - importante contribuição indireta -, enquanto Shackle e Hicks preenchem o último critério.

É claro que, mesmo com a adoção de tais critérios, não se eliminou inteiramente a necessidade de se fazer escolhas, até certo ponto arbitrárias. Os maiores riscos incorridos foram a não inclusão de J. Robinson e/ou de Georgescu-Roegen na lista de autores discutidos neste artigo, uma vez que não havia espaço para a incorporação de mais outro autor ao trabalho. O ponto de vista que prevaleceu foi o de que as contribuições destes dois grandes autores para o tema do tempo em economia, embora tenham sido inegavelmente relevantes, foram, entretanto, menos significativas e esclarecedoras do que as contribuições de Shackle e de Hicks, que completaram a lista dos autores abordados neste artigo.

A propósito, está última ponderação é aplicável também a outros autores que adotam a concepção não determinista do tempo e que têm contribuído para o seu

debate. Estes são os casos, por exemplo, de vários autores pós-keynesianos, schumpeterianos/evolucionistas e, até mesmo, de certos autores da nova escola austríaca.

\section{REFERÊNCIAS BIBLIOGRÁFICAS}

Amsterdamski, Stefan (1993) Causa/Efeito. Enciclopédia Einaudi, Vol. 33. Lisboa: Imprensa Nacional. Braudel, Fernand. (1996) Civilização Material, Economia e Capitalismo: Séculos XV-XVIII. Vol. 3: O

Tempo do Mundo. São Paulo: Martins Fontes.

Carvalho, Fernando de (1983) "Ontheconceptof time in ShackleanandSraffianeconomics", Journal of Post-keynesian Economics, vol. 6, n²:265-280.

Chick, Victoria (2010) Sobre Moeda, Método e Keynes. Campinas: Unicamp.

Coveney, Peter e Highfield, Roger (1993) A Flecha do Tempo. São Paulo: Siciliano.

Davidson, Paul (1996) "Reality and economic theory". Journal of Post-keynesian Economics.Vol. 18, $\mathrm{n}^{\circ}$ 4: $479-508$. 
Davidson, Paul (2011) John Maynard Keynes. São Paulo: Actual.

Davies, Paul (1995) About Time. Londres: Viking.

Davis, John B. et al.. (1998) The Handbook of Economic Methodology. Cheltenham: Edward Elgar.

Elias, Norbet (1998) Sobre o Tempo. Rio de Janeiro: Zahar

Georgescu-Roegen, Nicholas (1977) "What thermodynamics and biology can teach economics”, Atlantic Economic Journal, Vol. 5 n 1 1: 13-21.

Georgescu-Roegen, Nicholas. (1988) “Time and change in economics”. In: Seifert, Eberhard K. Okonomie und Zeit: Beitrangezurinterdisziplinarenzeitokonmie. Frankfurt: Haag Herchen.

Georgescu-Roegen, Nicholas (1994) “Time in Economics”. In: Hagemann, Harald et al.. The Legacy of Hicks: his contributions to economic analysis. Londres: Routledge.

Gould, Jay. S. (1987a) La Sonrisa Del Flamenco: Reflexiones Sobre Historia Natural. Madri: Hermann Blume.

Gould, Jay. S. (1987b) Darwin e os Grandes Enigmas da Vida. São Paulo: Martins Fontes.

Hansson, Björn. (1991) "The Stockholm School and the development of dynamic method”. In: Sandelin, Bo. The History of Swedish Economic Thought. Londres: Routledge.

Hicks, John. R. (1972). Rio de Janeiro: Zahar.

Hicks, John. R. (1976) “Some Questions of Time in Economics”. In: Tang, A. M. et al.. Evolution, Welfare and Time in Economics. New York: Heath.

Hicks, John. R. (1989) Métodos de Economia Dinámica. Cidade do México: Fondo de Cultura Económica.

Hicks, John. R. (1978) Perspectivas Econômicas. Rio de Janeiro: Zahar.

Hicks, John. R. (1979) Causality in Economics. New York: Basic Books.

Hobsbawm, Eric. (2014) Sobre História. São Paulo: Companhia das Letras.

Holanda Ferreira, A. B. (1975) Novo dicionário da língua portuguesa. Rio de Janeiro: Nova Fronteira.

Kauffman, S. (1993) Origins of order: self-organization and selection in evolution. Oxford: Oxford Press.

Kauffman, S. (1995) At Home in the universe: the search for laws of complexity. Londres: Vking Press. Keynes, John M. (1983) Teoria Geral do Emprego, do Juro e do Dinheiro. São Paulo: Abril Cultural.

Keynes, John M. (1978). “A Teoria Geral do Emprego”. In:Szmrecsányi, Tamás. Keynes. Coleção Grandes Cientistas Sociais. São Paulo: Edit. Ática.

Keynes, John M. (1972). The Collected Writings of John Maynard Keynes. Vol. X Essays in Biography. Londres: Macmillan.

Klein, Burton H. (1977) Dynamic Economics. Cambridge: Harvard Press.

Knight, Frank. H. (1972) Risco, Incerteza e Lucro. Rio de Janeiro: Expressão e Cultura.

Mäki, Uskali. ePiimies, Jukka-Pekka (1998) “CeterisParibus”. In: Davis, John. B. et al.. The Handbook of Economic Methodology. Cheltenham: Edward Elgar.

Marshall. Alfred. Vols. I e II (1982) Princípios de Economia. São Paulo: Abril Cultural.

Mayr, Ernst (2008) Isto é Biologia. São Paulo: Companhia das Letras.

Mayr, Ernst (2009). O que é Evolução. Rio de Janeiro: Rocco.

Milgate, Murray (1987) "Equilibrium: development of the Concept". The New Palgrave Dictionary of Economics. Londres: Palgrave Macmillan.

Mirowski, Philip (1989) More Heat than Light: Economics as Social Physics, Physics as Nature's Economics. Cambridge: Cambridge Press.

O’Driscoll, G. P. e Rizzo, M. J. (2002) The Economics of time and ignorance. Londres: Routledge.

Panico, C. e Petri, F. (2008) “Long Run and Short Run”. The New Palgrave Dictionary of Economics. Londres: Macmillan.

Pomian, Krzysztof. (1993a) “Tempo/Temporalidade”. Enciclopédia Einaudi Vol. 29. Lisboa: Imprensa Nacional.

Pomian, Krzysztof. (1993b) “Ciclo”. Enciclopédia Einaudi Vol. 29. Lisboa: Imprensa Nacional.

Popper, Karl. (1982) The Quantum Theory and the Schism in Physics. Totowa: Rowman and Litllefield.

Popper, Karl. (1956) “The Arrow of time”. Nature, Vol. 177: 538. 
Popper, Karl. (1957) “Irreversibility; or, entropy since 1905”. British Journal for the Philosopy Science8 (30): $151-155$.

Popper, Karl. (1967) "Structural information and the arrow of time". Nature, vol. 214: 322.

Prado, E. F. S. (2014) Economia e Complexidade. Tomo III. São Paulo: Plêiade.

Prigogine, Ilya (1996) O Fim das Certezas. São Paulo: Unesp.

Prgogine, Ilya e Stengers, Isabelle (1997) A Nova Aliança. Brasília: Universidade de Brasília.

Prigogine, Ilya (2002) As Leis do Caos. São Paulo: Unesp

Robinson, Joan (1979) Contribuições à Economia Moderna. Rio de Janeiro: Zahar.

Robinson, Joan (1988) Novas Contribuições à Economia Moderna. São Paulo: Vértice.

Ruelle, D. (1993) Acaso e Caos. São Paulo: Unesp.

Schrödinger, Erwin (1977) O que é vida? O aspecto físico da célula viva. São Paulo: Unesp.

Schumpeter, Josehp A. (1984) Capitalismo, Socialismo e Democracia. Rio de Janeiro: Zahar.

Schumpeter, Josehp A. (1994) History of Economic Analysis. New York: Oxford Press.

Schumpeter, Josehp A. (1958) Dez Grande sEconomistas. Rio de Janeiro: Civilização Brasileira.

Shackle, George L.S. (1976) Epistemica Y Economia: Crítica de las Doctrinas Económicas. Cidade do México: Fondo de Cultura Economica.

Shackle, George L.S. (1969) Um Esquema De Teoria Econômica. Rio de Janeiro: Zahar.

Shackle, George L.S. (1959) "Time and thought", The British Journal for the Philosophy of Science, Vol. 9 , n 36 (Feb., 1959), pp. 285-298. Acessado em 12/07/2012.

Shackle, George L.S. (1966) Decisión, Ordeny TiempoenlasActividades Humanas. Madri: Tecnos.

Shackle, George L.S. (1990) Time, expectations and uncertainty in economics: selected essays. Aldershot: Edward Elgar.

Shackle, George L. S. (1976) “Time and choice”. Republicadoem Shackle (1990) Time, expectations and uncertainty in economics: selected essays. Aldershot: Edward Elgar.

Shackle, George L. S. (1991) Origens da Economia Contemporânea: Invenção e Tradição no Pensamento Econômico (1926-1939).São Paulo: Hucitec.

Silverberg, G. (1988). "Modellingeconomic dynamics and technical change: mathematical approaches to self-organisation and evolution". In: Dosi, G. et al.. The Technical change and economic theory. Londres: Pinter Publishers.

Steiger, Otto. (1987) "Ex ante and Ex post”. Palgrave Dictionary of Economics. Londres: Macmillan.

Streeten, Paul. (1987) “Myrdal, Gunnar”. Palgrave Dictionary of economics. Londres: Macmillan.

Whitaker, J. K. (1987a) “Ceteris Paribus”. Palgrave Dictionary of Economics. Loners: Macmillan.

Whitaker, J. K. (1987b) “Marshall, Alfred”. Palgrave Dictionary of Economics. Londres: Macmillan.

Whitaker, J. K. (1996) “The Emergence of Marshall's Period Analysis”. In: Ed. Wood, John. C. Alfred Marshall: critical assessments second series. Londres: Routledge.

Whitrow, Gerald J. (2005) O que é o Tempo? Rio de Janeiro: Zahar. 